\title{
Leaf turnover and herbivory in the tall tussock grass Festuca orthophylla in the Andean Altiplano
}

\author{
José Alberto Fernandez Monteiro • Christian Körner
}

Received: 16 October 2012/Accepted: 2 March 2013/Published online: 22 March 2013

(C) Swiss Botanical Society 2013

\begin{abstract}
Tall grass tussocks dominate the Andean highlands above $3,800 \mathrm{~m}$ a.s.l., with often no other life form contributing significantly to standing crop biomass and productivity, thus, representing the dominant source of fodder for camelid grazing. To assess the productivity of these semi-arid tropical rangelands $(350 \mathrm{~mm}$ of annual rainfall confined to a 4-5 months rainy season) is challenging, given the 'evergreen' nature of leaves and the unknown periodicity of leaf growth. The aim of this study was to explore the seasonal course of new foliage formation, foliage duration, and the response of leaf elongation and emergence to simulated llama grazing (clipping). The repeated census of Festuca orthophylla leaves in the Sajama National Park at 4,250 m elevation (Bolivia) provided clear evidence that leaf production is not confined to the rainy season, but also occurs during the dry season. Our data revealed a mean leaf longevity of 141 days for peripheral control tillers (unclipped) and 169 days for central control tillers. Leaves grow slower and reach shorter length during the dry season compared to the rainy season, and peripheral tillers are always shorter but more vigorous than central tillers (shorter intervals between the emergence of two leaves). There was no stimulation of leaf growth in tillers that were clipped (no overcompensation). Overall, this study suggests ca. two-fold replacement of foliage per year. We explain the continued growth in the dry season by, on average, six times greater soil area occupied by roots than by the leaf canopy, and thus, much greater water availability per tussock than meteorological data would suggest. Wide spacing of tussocks and a large
\end{abstract}

J. A. F. Monteiro $(\bowtie) \cdot$ C. Körner

Institute of Botany, University of Basel, Schönbeinstrasse 6, 4056 Basel, Switzerland

e-mail: jose.monteiro@gmx.ch root-sphere mitigate the impact of periodic drought on tissue formation, providing year-round forage for llamas.

Keywords High elevation - Leaf longevity · Semi-arid grassland $\cdot$ Subtropical

\section{Introduction}

In perennial tropical grassland, productivity cannot be assessed by conventional harvesting, but requires knowledge of leaf turnover. It makes a big difference whether, at a given leaf area index, leaves operate for a few weeks only or for more than a year. Further, it is key to know whether leaf renewal is perennial (continuous) or confined to certain periods of the year. Hence, quantifying the dynamics of leaf populations is an essential first step in any attempt at assessing productivity and plant-herbivore interaction. This paper is offering such data for one of the highest elevation grassland ecosystems of the world.

Herbivory has been a major ecological factor, for as long as fossil records for vascular plants are available (Chaloner et al. 1991). The long interaction between plants and herbivores has selected for plants that can avoid or tolerate the removal of biomass, and on the other hand, herbivores that can cope with plant's mechanical (e.g. spines, sclerophylly) or chemical defences (e.g. terpenes, toxins) or low dietary quality. Defoliation may have stimulating or retarding effects on plant growth. A compensatory stimulation of growth may result from a suite of effects, such as a reduction of self-shading, increase in nutrient availability, and an improvement of the water status of the remaining tissues. The ontogenetic decline in photosynthesis, a smaller fraction of senescent foliage, less new root growth, and a hormonal stimulation of apical meristems may further 
contribute to compensatory growth enhancement (Crawley 1998; Dyer et al. 1993; McNaughton 1983a, b). Yet, there is no consensus whether a stimulation of growth in response to defoliation is a general response as is often assumed (Belsky et al. 1993; Crawley 1987). Different scales of measurements (spatial and temporal; Belsky 1987; Belsky et al. 1993), and the different currencies (above-ground net production versus Darwinian fitness; Crawley 1998) may affect results. Additionally, the term 'compensatory growth' is used in a very broad sense, ranging from a partial or complete substitution of the lost tissue, to an increase in biomass production (regrowth) beyond control rates in grazed compared to undisturbed vegetation (see the definition in methods, following Strauss and Agrawal 1999). Responses may further differ depending on whether whole plants are treated (like in the case of mowing) or when individual shoots or tillers are removed, with intact neighbour foliage.

According to the herbivore optimization hypothesis (Dyer et al. 1982), a moderate grazing level tends to increase the above-ground net primary production or fitness of grazing-tolerant plants. Nevertheless, the literature that evidences a consistent increase of biomass production due to grazing is meagre (Crawley 1987; Westoby 1989). Milchunas et al. (1988) developed a model to predict the effects of grazing by large herbivores in grasslands, based on gradients of moisture availability versus evolutionary history of grazing. The model was later validated by a meta-analysis based on a worldwide, 236-site data set, compiled from studies evaluating the impact of grazing on vegetation (Milchunas and Lauenroth 1993). The study revealed that semi-arid grasslands with a long evolutionary history of grazing, low primary production, and low-to-moderate grazing pressure are the most likely systems in which a stimulation (overcompensation) in biomass production in response to defoliation might occur.

Over the whole Andean Altiplano, the husbandry of camelids is still practiced in the traditional way, where animals graze freely across the landscape during the day, and are gathered into krals at night. Llamas and alpacas have been selected from wild camelids since ancient time, with livestock peak in the XI and XII centuries during the Inca Empire (Cardozo 2007). The natural Altiplano pasture consists of the tall tussocks of Festuca orthophylla, the dominant species in the dry pajonales, that covers vast rangeland areas between 3,600 and 4,680 m a.s.l. (Monteiro et al. 2011). Shrub species from the genera Baccharis and Parastrephia are far less frequent, and small annual and perennial herbs emerge only during the rainy season of the austral summer. This intra-tussock vegetation plays a role in animal nutrition due to the high nitrogen content, but its biomass contribution is minute (Patty et al. 2010). Festuca orthophylla is the principal component of the ecosystem's primary production and has major importance for the livestock's diet. A management of the pastures is almost inexistent, with the exception of burning of old tussock individuals. However, the benefits of fire are controversial, as the post-fire regrowth is severely affected by grazing, and rather slow even under animal exclusion (Mark 1994).

The long history of plant-animal interaction may have led to adaptations of Festuca tussocks to regular grazing, and a compensatory stimulation of growth could be one of the adaptive responses, together with physiological adaptations to the semi-arid climate of the Altiplano.

We hypothesized that clipping (simulation of grazing) should accelerate growth in Festuca orthophylla, and we simulated grazing by clipping leaves on individual tillers among other, non-clipped tillers. Camelids do not graze entire tussocks but pick individual leaves or small groups of leaves, similar to how we clipped the experimental tillers. Accordingly, we asked the following questions: (1) what is the mean renewal rate (longevity) of tussock foliage?, (2) does clipping of the fully expanded leaves accelerate the growth and increase the longevity of the next leaf on the same tiller?, and (3) does clipping enhance the rate of leaf emergence in a given tiller? In addition, we explored whether leaf dynamics and clipping responses differ for tillers in the centre and in the periphery of the tussocks. This differentiation is important in the context of tussock expansion.

\section{Materials and methods}

\section{Study area}

In the western part of the Bolivian Altiplano, close to the Chilean border, high mountain wildlife has been protected along an elevational range 4,200-6,542 $\mathrm{m}$ a.s.l. since the declaration of Sajama National Park (S $18^{\circ} 08^{\prime}$ W $\left.68^{\circ} 58^{\prime}\right)$ in 1939. In spite of its protected status, more than 5,000 indigenous inhabitants (census of 2002) are allowed to continue the traditional camelid husbandry (llamas and alpacas) in the lower parts of the park. The humid depressions represent the so-called 'bofedales', with full cover of short-stature vegetation. The more abundant, slightly elevated terrain is well drained, and dominated by Festuca orthophylla ('pajonales') a tall, widely spaced tussock grass (land cover $=14.4 \%$ ).

This semi-arid region is characterized by year-round low temperatures: daily means are $2.3{ }^{\circ} \mathrm{C}$ for 'winter' and $10.7{ }^{\circ} \mathrm{C}$ for 'summer' (rainfall season). Temperature seasonality is low, but the diurnal amplitude is very high $(8.6 \%$ of the days showed an amplitude in air temperature of more than $30 \mathrm{~K}$ between 2003 and 2008; Monteiro et al. 2011). The annual precipitation is $300-350 \mathrm{~mm}$ (Hardy et al. 1998), and is concentrated between November and March, with most and the heaviest rainfall in January and February. 
The dry, cloudless winter without snow cover increases evaporative demand, accentuating the aridity of the region.

Plant material, measurements, and definitions

For this study, initiated on February 13, 2008, we used fenced test plots that have excluded animals since April 2006 (Monteiro et al. in preparation). In each of the four fenced plots, we selected four representative tussocks (mean diameter $43 \pm 7 \mathrm{~cm}$, height $58 \pm 12$; mean $\pm \mathrm{SD}$ ) to assess the seasonal leaf expansion and the response of individual tillers to defoliation (Fig. 1). In each plant, we marked eight tillers with a recent, just emerging leaf, using coloured plastic beads: four tillers close to the centre of the tussock, and other four at the periphery. To simulate grazing, half of the tillers were clipped, i.e. all fully expanded leafblades were cut above the leaf's ear, leaving only $3 \mathrm{~cm}$ of the blade, but the youngest expanding leaf-blade $(<3 \mathrm{~cm}$ visible; L1) in each tiller was left intact. We measured the length of this newly expanding leaf (L1), using the ear of the second youngest, fully expanded leaf as a reference. Marked tillers were revisited periodically (5- to 20 -day intervals over a period of 188 consecutive days) to measure the length of the youngest leaf, and note its phenological state (green, senescent, or dead). The same traits were recorded for a second cohort of emerging leaves (L2) later in the year. Leaves emerge from the sheath of older leaves, and we considered a leaf as 'emerged' when a leaf tip longer than $1 \mathrm{~mm}$ became visible. Time to leaf emergence is defined as

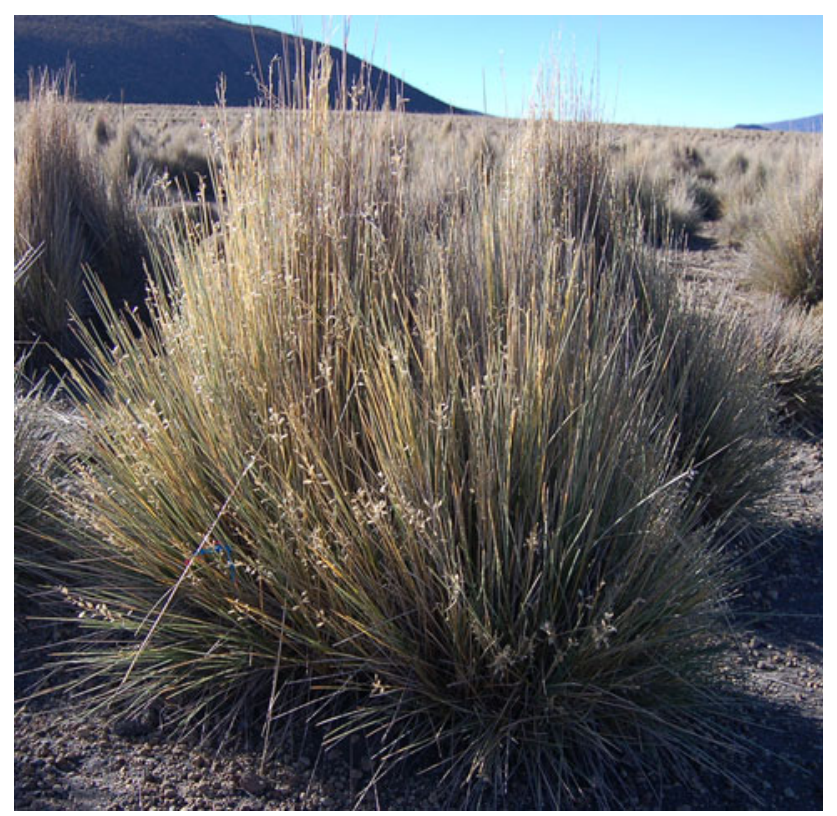

Fig. 1 Typical-sized tussock (0.6 m height) of Festuca orthohylla in the Sajama National Park (4,250 m a.s.l.) in the Bolivian Altiplano the period between the dates of emergence of two successive cohorts of leaves.

For this experiment, we used 8 marked tillers in each of 16 tussocks. Of these 8 tillers, each of 2 tillers had the same combination of treatment $\times$ position (so the replicates were the tussocks, i.e. $n=16$ ), and the value used for statistics was the average of these two tillers with the same combination of treatment $\times$ position per tussock. Leaves that died suddenly during the expansion were excluded from the analysis.

To describe the response to clipping, we employed the same definitions as suggested by Strauss and Agrawal (1999): undercompensation, compensation, or overcompensation. Compensation means that leaves are growing at similar rates after clipping than leaves on unclipped tillers, and undercompensation and overcompensation refer to a reduction or increase in leaf growth rates compared to controls. In many earlier works, overcompensation has been addressed as 'compensatory growth'.

\section{Statistics}

We used a best-fit (coefficients ' $a$ ' and 'b') exponential function to obtain the growth curve for each individual leaf studied $($ Leaf length $=$ final length $+\mathrm{a} \times \exp (-\exp (\mathrm{b}) \times$ day). With these curves, we regressed the date of leaf emergence (length $=0$ ) of the first and second leaf cohort. For each leaf, we calculated the slope of the initial growth rate (using the first and second length measurement) and the final leaf length (leaf blade only). The initial growth rate assessed this way is a conservative estimate, because the second reading had sometimes been taken when leaves had already been quite long. We also calculated the interval between the emergence of the first and second cohort of leaves. For a graphical illustration, we averaged the parameters 'final length', 'a' and 'b' of the individual leaf regressions to calculate a mean regression, with the confidence intervals represented by the regressions produced with either + or - the standard error of each coefficient and final leaf length. The onset of leaf senescence and leaf longevity were measured in the first leaf cohort only. When the census was completed, all initially marked leaves had senesced. Of these, $60 \%$ were completely desiccated, and the remaining leaves had died back as well, but retained a 1-3 cm live base for a long time, not likely to play any significant role in carbon assimilation. We considered all leaves that reached this state dead as well.

We followed the protocol of Zuur et al. (2009; pp. 90-92) for the statistical analysis. All parameters were analysed with fixed-effect models, and the fixed factors were tiller position (centre vs. periphery) and treatment (control vs. clipped). The only parameter for which a transformation was needed was the final leaf length for the second leaf cohort, 
and the transformation used was $\log 10$. We further used a mathematical function (varIdent in $\mathrm{R}$ ) to correct for differences in the variance structure across these fixed factors, thereby balancing the weight of variances across fixed factors. This method is recommended when variances differ at the level of classification (fixed factors and groups of fixed factors; Pinheiro and Bates 2000). All statistics and graphics were carried out with R (R Development Core Team 2009).

\section{Results}

The leaf dynamics data revealed a 141-169 days leaf duration (peripheral vs. central control leaves; Table 1) and a surprising continuation of leaf expansion and emergence during the long dry season. There is a clear distinction in vigour between peripheral and central tillers, the latter ones being larger, but 'slower' than the first $(P<0.001$; Table 2$)$. It follows from the tussock's architecture (Fig. 1) that central tillers are longer and also have longer leaf blades than peripheral tillers $(P<0.001)$, and therefore it is not possible to separate the effect of position from the effect of the length of the tiller as such, but we consider the confounding of size and position of tillers intrinsic to the way these tussocks are shaped.

Initial leaf expansion rate in $F$. orthophylla rather seemed to be determined by tiller position in the tussock during the rainy season, with leaves of more central tillers expanding faster in absolute terms than leaves of peripheral tillers $(P<0.001)$. In relative terms (expressed as a fraction of final leaf length), initial rate of elongation differed less between central and peripheral tillers (data not shown). However, in the dry season, there was no difference in the absolute elongation rate of tillers with different position, hence, in relative terms, leaves in central tillers grew slower. Accordingly, the final length leaves reached in the rainy season was determined by tiller position, with central tillers producing longer leaves (ca. $+59 \%$ ) than peripheral tillers $(P<0.01)$. The position difference in final leaf length was retained in the dry season $(P<0.001)$, but was smaller $(+28 \%$ longer leaves in central tillers).

The onset of leaf senescence was similar for leaves in central or peripheral positions, starting at day $90-96$ of a leaf's life $(P=0.121)$. Nevertheless, leaves on central tillers lived longer than leaves on peripheral tillers $(P<0.001)$. Moreover, the interval between the emergence of two consequent leaves in the same tiller was larger for central tillers in comparison to peripheral tillers $(P<0.001)$. Hence, leafing was more dynamic, but structures were more stunted at the periphery, explaining the shape of these tussocks (Fig. 1).

Clipping had very little effect on leaf dynamics. Initial leaf elongation rate was not different in leaves from clipped tillers compared to controls, neither in the rainy season, $\mathrm{L} 1$, nor in the dry season, L2 $(P=0.404$ and $P=0.716$, respectively). However, during the dry season there was an interaction between position and clipping for the initial rate of leaf elongation: clipping slowed absolute leaf elongation in central tillers but accelerated it in peripheral tillers $(P=0.011)$. During the rainy season, clipped tillers showed a trend in producing shorter leaves than control tillers $(P=0.081)$ and the same trend persisted in the dry season $(P=0.072)$. Finally, the onset of senescence was delayed in clipped tillers (observations restricted to the rainy season; $P=0.020$ ), but clipping had no effect on leaf longevity $(P=0.278)$ nor on the time laps between L1 and L2 leaf $P=0.404$ ).

Overall, with the exception of delaying the onset of leaf senescence, there were no clipping effects on leaf dynamics of tillers of $F$. orthophylla, but leaf turnover was more rapid in the periphery of the tussock irrespective of the treatment (shorter longevity and shorter interval between consecutive leaf cohorts; Fig. 2).

Table 1 Dynamics and traits of leaves of Festuca orthophylla from non-clipped (control) or clipped tillers in central or peripheral position $\left(\right.$ mean $\pm \mathrm{SD} ; n=16$ tussocks $^{\mathrm{a}}$ )

\begin{tabular}{|c|c|c|c|c|}
\hline & \multicolumn{2}{|l|}{ Centre } & \multicolumn{2}{|l|}{ Periphery } \\
\hline & Control & Clipped & Control & Clipped \\
\hline Initial leaf elongation rate $\left(\mathrm{mm} \mathrm{day}^{-1} ; \mathrm{L} 1\right)$ & $3.8 \pm 0.9(16)$ & $3.6 \pm 1.0(16)$ & $2.7 \pm 1.0(15)$ & $2.3 \pm 0.7$ \\
\hline Initial leaf elongation rate $\left(\mathrm{mm} \mathrm{day}^{-1} ; \mathrm{L} 2\right)$ & $3.0 \pm 0.9(16)$ & $2.7 \pm 1.0(14)$ & $2.7 \pm 0.8(14)$ & $3.3 \pm 1.1(13)$ \\
\hline Final leaf length (cm: L1) & $17.0 \pm 3.0(16)$ & $16.3 \pm 4.2(16)$ & $10.6 \pm 3.0(15)$ & $10.3 \pm 3.3(14)$ \\
\hline Final leaf length (cm; L2) & $11.3 \pm 3.1(16)$ & $9.8 \pm 2.0(10)$ & $8.4 \pm 1.4(14)$ & $8.1 \pm 1.7$ \\
\hline Beginning of senescence (L1; day) ${ }^{b}$ & $96 \pm 17(16)$ & $105 \pm 16(16)$ & $90 \pm 24(15)$ & $101 \pm 18$ \\
\hline Longevity (L1; day) & $169 \pm 31(16)$ & $175 \pm 20(16)$ & $141 \pm 42(15)$ & $149 \pm 30(14)$ \\
\hline Time to leaf emergence (L2; day) ${ }^{\mathrm{b}}$ & $54 \pm 15(16)$ & $52 \pm 16(10)$ & $40 \pm 12(14)$ & $38 \pm 8(13)$ \\
\hline
\end{tabular}

L1 and L2 refer to the first (rainy season) and the second (beginning of dry season) leaf cohort after the beginning of the experiment

${ }^{\text {a }}$ Leaves that died during elongation, or leaves that were too young to calculate all parameters were not used

b Measured as leaf age in days, and not days of the year 
Table 2 Analysis of variance for final leaf length and initial leaf elongation rate of two cohorts of leaves (L1 and L2) in control or clipped tillers, at central or peripheral position in the Festuca orthophylla tussock ( $n=13-16$ tussocks)

\begin{tabular}{|c|c|c|c|c|}
\hline Response variable & Factor & DF & $F$ value & $p$ value \\
\hline \multirow[t]{3}{*}{ Initial leaf elongation rate (L1) } & Clipping & 1 & 0.71 & 0.404 \\
\hline & Position & 1 & 26.67 & $<0.001$ \\
\hline & Clipping $\times$ Position & 1 & 0.18 & 0.671 \\
\hline \multirow[t]{3}{*}{ Initial leaf elongation rate (L2) } & Clipping & 1 & 0.13 & 0.716 \\
\hline & Position & 1 & 1.14 & 0.292 \\
\hline & Clipping $\times$ Position & 1 & 7.19 & 0.011 \\
\hline \multirow[t]{3}{*}{ Final leaf length (L1) } & Clipping & 1 & 3.21 & 0.081 \\
\hline & Position & 1 & 63.00 & $<0.001$ \\
\hline & Clipping $\times$ Position & 1 & 0.06 & 0.813 \\
\hline \multirow[t]{3}{*}{ Final leaf length $\left(\mathrm{L} 2 ; \log _{10}\right)$} & Clipping & 1 & 3.43 & 0.072 \\
\hline & Position & 1 & 25.17 & $<0.001$ \\
\hline & Clipping $\times$ Position & 1 & 1.32 & 0.259 \\
\hline \multirow[t]{3}{*}{ Beginning of senescence (L1) } & Clipping & 1 & 5.90 & 0.020 \\
\hline & Position & 1 & 2.51 & 0.121 \\
\hline & Clipping $\times$ Position & 1 & 0.13 & 0.713 \\
\hline \multirow[t]{3}{*}{ Leaf longevity (L1) } & Clipping & 1 & 0.84 & 0.278 \\
\hline & Position & 1 & 14.98 & $<0.001$ \\
\hline & Clipping $\times$ Position & 1 & 0.16 & 0.902 \\
\hline \multirow[t]{3}{*}{ Time to leaf emergence (L2) } & Clipping & 1 & 0.71 & 0.404 \\
\hline & Position & 1 & 16.53 & $<0.001$ \\
\hline & Clipping $\times$ Position & 1 & 0.000 & 0.996 \\
\hline
\end{tabular}

\section{Discussion}

The results of this assessment of leaf dynamics in tall Altiplano tussock grasses revealed a 4.7-5.6 months leaf duration and a surprising continuation of leaf expansion and emergence during the long dry season. Leaf dynamics were closely related to the position of tillers. We observed a rather linear leaf elongation that stopped quite abruptly when
Fig. 2 Time course of leaf elongation for two leaf cohorts (L1 and L2) per tiller in 13-16 tussocks of Festuca orthophylla (mean $\pm \mathrm{SE}$ ). For L1, the dotted line indicates the period of senescence, and the right end indicates leaf death. Open circles are the means for $\mathrm{L} 1$ and filled circles are the means for L2. Triangles below the curves indicate first observations of a third cohort of leaves emerging during the later dry season (i.e. emergence occurred between this date and the previous observation; insufficient data to calculate a trustworthy mean response)

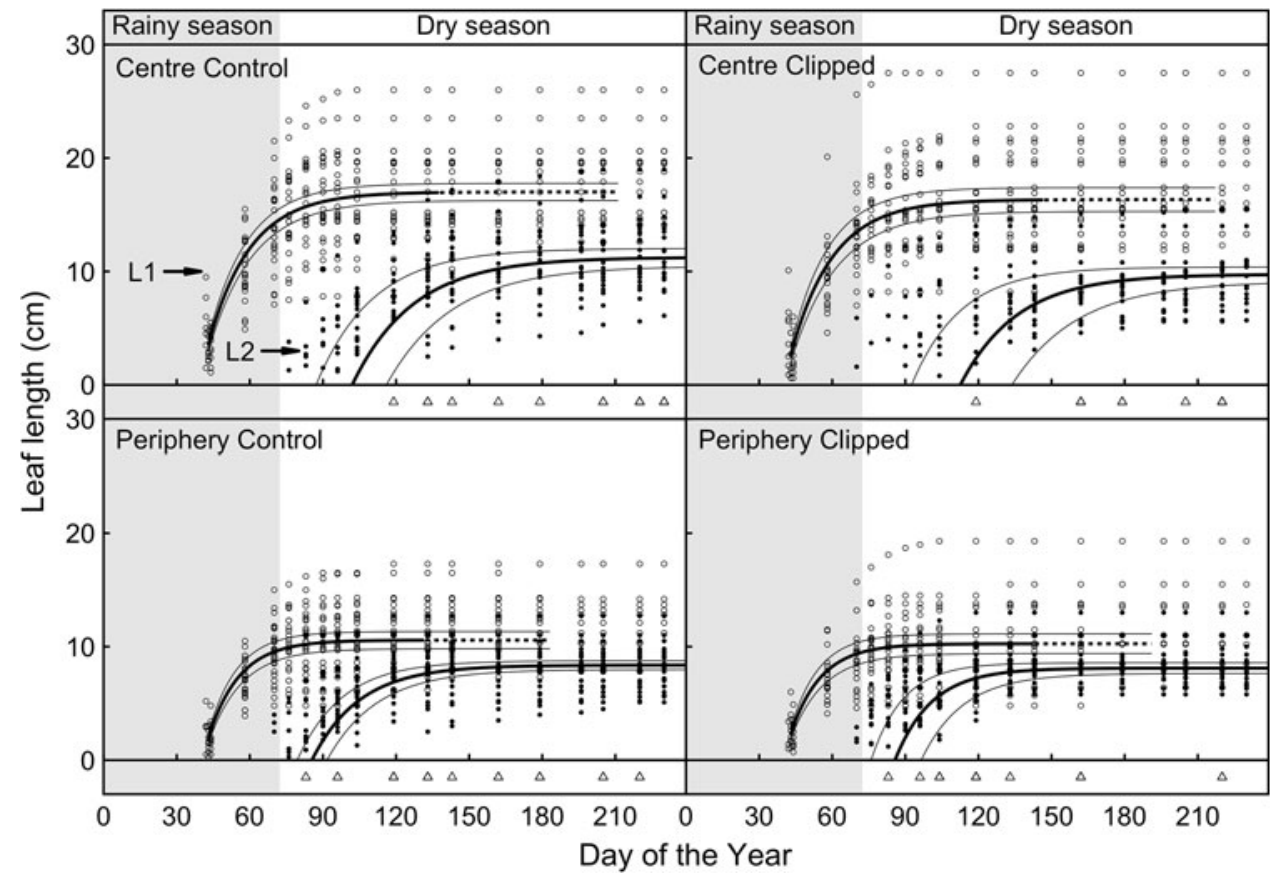


leaves reached their maximum size in the first cohort (wet season), in contrast to the findings for Calamagrostis effusa (Hofstede et al. 1995), in which expansion rate decreased gradually with increasing leaf length.

As discussed in the introduction, overcompensatory growth in response to either artificial (clipping) or natural foliage removal (grazing, browsing) is not a universal response. Our finding that new leaves on clipped tillers grew as fast as new leaves in unclipped tillers is similar to observations in Nardus stricta where leaf dynamics in individual ramets containing several tillers (0-3 inter-connected neighbour tillers clipped, Grant et al. 1996), also showed no clipping effect along a clipping gradient. In contrast, narrow-leaved tall tussocks of Chionochloa rigida (in New Zealand, similar in size and stature to $F$. orthophylla) showed a $21 \%$ growth stimulation (new leaf elongation) compared to controls after almost complete removal of leaf blades from a tussock (Rowley 1970). Hofstede et al. (1995) found a reduction of initial leaf expansion rate with increasing grazing intensity in Calamagrostis effusa tussocks in the Colombian Páramos. It seems, the intensity of clipping/grazing makes a substantial difference. Near to complete defoliation is a rather radical treatment not matching the camelids' grazing behaviour. On the other hand, it remains to be shown if re-growth would be stimulated if a greater fraction of tillers (rather than just two) in a given tussock would be clipped/grazed. We can only conclude that there is no tiller specific response.

Clipping had only a marginally significant effect on the final length of the two generations of leaves studied. In both cases, leaves growing in clipped tillers tended to be shorter. Shorter leaves in response to clipping were also reported for potted Poa liguralis of the Patagonian arid steppe and in grazed Kobresia myosuroides in an alpine meadow in Yucon, Canada (respectively, McIntire and Hik 2002; Rotundo and Aguiar 2008). However, both Poa liguralis and Kobresia myosuroides compensated for the shorter leaves, by producing more leaves per tiller. Accordingly, increasing clipping intensity in Leymus chinensis resulted in decreasing final shoot length, and tillering decreased only in $100 \%$ clipped individuals in one of two studied years, and resulted in a generally lower biomass accumulation in clipped plants (Liu et al. 2012).

The rate of new leaf emergence was not enhanced in clipped $F$. orthophylla tillers, but we cannot exclude a faster rate of tillering (not studied here). In the more peripheral tillers, leaf emergence generally occurred earlier than in more central tillers, irrespective of clipping treatment, which may compensate for their somewhat shorter size compared to more central tillers. In Festuca orthophylla, the only trait of leaf dynamics that responded to clipping in an overcompensatory way was the beginning of senescence, with new leaves of formerly clipped tillers delaying senescence, although final leaf duration was not affected.

The responses of Festuca orthophylla to drought clearly contrast to other reports of a cessation of leaf elongation during the dry season for tussocks living in arid environments (Busso and Richards 1993; Busso and Richards 1995; Pugnaire et al. 1996). Although initial leaf elongation rates tended to be slower in $F$. orthophylla during drought, leaf blade elongation and leaf emergence were never completely suspended till late in the dry season (even the emergence of a third leaf cohort was observed; Fig. 2). The sustained growth of $F$. orthophylla during the long rainless season may reflect adequate water availability as has been already implied by the transpiration studies by Geyger (1985). The wide root sphere of the tussocks, which expands into bare inter-tussock land, significantly beyond the tussock canopy's periphery (Monteiro et al. 2011), may hold the explanation. The use of this extra land area for moisture uptake is also the likely explanation why biomass production is larger than expected from rainfall data. Further, the prioritizing of peripheral tillers (shorter interval between two successive cohorts and lower effect of drought on the initial rate of leaf elongation) over central tillers may result from a larger intra-tussock competition or greater clonal age in the old centre compared to the young periphery. In Eragrostis curvula, the removal of either live leaves or dead plant material stimulated tiller recruitment in the centre of the tussock compared to undisturbed tussocks, indicating that the tussock centre is a highly competitive environment, with both space constraints (crowding) and light extinction as important drivers (Monteiro et al. 2011; Ursino 2009).

Leaf longevities of about half a year are quite common in perennial alpine plants in a tropical environment. Diemer (1998) reported $193 \pm 19$ days for several species in the Ecuadorian Paramos at ca. 4,000 m elevation, and with much shorter duration of only 41-95 days (68 \pm 4 days) in 29 herbaceous perennials in 2,600 $\mathrm{m}$ a.s.l. in the Alps (Diemer et al. 1992). In the current study, we assessed leaf longevity during the rainy and early dry season. Drought may enhance longevity as was shown for semi-arid regions (Casper et al. 2001; Sandquist and Ehleringer 1998). Assuming that the dry season leads to prolonged leaf duration in F. orthophylla (the longevity of L2 was not explored here), the average longevity across the year would be larger than reported here. Finally, since the total green leaf biomass of these tussocks is ca. $170 \mathrm{~g} \mathrm{~m}^{-2}$ (dry mass) of land area (unpublished data of Monteiro 2010), a leaf turnover of half a year would yield a total green leaf production of $340 \mathrm{~g} \mathrm{~m}^{-2}$ land area $\mathrm{a}^{-1}$. This estimate does not account for the production of leaf sheets, tillering and flowering, and hence may be seen as a conservative, low-end estimate of the forage productivity of this landscape. 
In conclusion, this study evidenced a ca. half year leaf duration/turnover and continuation of leafing and leaf elongation during the long dry season. Partial foliage removal (as it occurs during camelid grazing) did not result in a stimulation in growth rate (no overcompensation) in Festuca orthophylla. Nevertheless, we believe that clipping was 'sensed' by tillers, since it delayed the onset, but accelerated the progression of leaf senescence, so, overall longevity was not affected. The results underline the efficient ways of moisture and space utilization in these tussocks. Wide spacing presumably permits greater moisture availability per tussock and, thus, permits year-round production of new foliage (fodder) in this semi-arid high elevation ecosystem.

Acknowledgments We are very grateful for permission and support by the Sajama National Park authorities to conduct this research. We thank Erika Hiltbrunner for her support and advice, Julieta Carilla for her help during several field campaigns, and Judith Trunschke for comments on the first version of this manuscript. This research was funded jointly by the Swiss National Science Foundation (SNSF, grant No. 3170A0-109806/1) and the Swiss Developmental Council (SDC), and was conducted in cooperation with the Universidad Mayor de San Andrés and the Bolivian National Herbarium (both in La Paz) with the support by Stephan Beck particularly acknowledged.

\section{References}

Belsky AJ (1987) The effects of grazing: confounding ecosystem, community, and organism scales. Am Nat 129:777-783

Belsky AJ, Carson WP, Jensen CL, Fox GA (1993) Overcompensation by plants: herbivore optimization or red herring? Evol Ecol 7:109-121

Busso CA, Richards JH (1993) Leaf extension rate in two tussock grasses: effects of water-stress and clipping. Acta Oecol 14:3-15

Busso CA, Richards JH (1995) Drought and clipping effects on tiller demography and growth of two tussock grasses in Utah. J Arid Environ 29:239-251

Cardozo A (2007) Camélidos. Impresiones Poligraf, Sucre

Casper BB, Forseth IN, Kempenich H, Seltzer S, Xavier K (2001) Drought prolongs leaf life span in the herbaceous desert perennial Cryptantha flava. Funct Ecol 15:740-747

Chaloner WG, Scott AC, Stephenson J (1991) Fossil evidence for plant-arthropod interactions in the paleozoic and mesozoic. Philos Trans Roy Soc Lond Ser B Biol Sci 333:177-186

Crawley MJ (1987) Benevolent herbivores. Trends Ecol Evol 2:167-168

Crawley MJ (1998) Herbivory. In: Press MC, Scholes JD, Barker MG (eds) Physiological plant ecology. British Ecological Society, London, pp 199-217

Diemer M (1998) Leaf lifespans of high-elevation, a seasonal Andean shrub species in relation to leaf traits and leaf habit. Glob Ecol Biogeogr 7:457-465

Diemer M, Körner C, Prock S (1992) Leaf life spans in wild perennial herbaceous plants: a survey and attempts at a functional interpretation. Oecologia 89:10-16

Dyer MI, Detling JK, Coleman DC, Hilbert DW (1982) The role of herbivores in grasslands. In: Estes JR, Tyr RN, Brunken JN (eds) Grasses and grasslands: systematics and ecology. University of Oklahoma Press, Norman, pp 255-295
Dyer MI, Turner CL, Seastedt TR (1993) Herbivory and its consequences. Ecol Appl 3:10

Geyger E (1985) Untersuchungen zum Wasserhaushalt der Vegetation im nordargentinischen Andenhochland. $\mathrm{PhD}$ Thesis, Universität Göttingen, Göttingen, Germany

Grant SA, Torvell L, Sim EM, Small JL, Elston DA (1996) Seasonal pattern of leaf growth and senescence of Nardus stricta and responses of tussocks to differing severity, timing and frequency of defoliation. J Appl Ecol 33:1145-1155

Hardy DR, Vuille M, Braun C, Keimig F, Bradley RS (1998) Annual and daily meteorological cycles at high altitude on a tropical mountain. Bull Am Meteorol Soc 79:1899-1913

Hofstede RGM, Chilito EJ, Sandovals EM (1995) Vegetative structure, microclimate, and leaf growth of a paramo tussock grass species, in undisturbed, burned and grazed conditions. Vegetatio 119:53-65

Liu JS et al (2012) Plants can benefit from herbivory: stimulatory effects of sheep saliva on growth of Leymus chinensis. PLoS One 7:e29259

Mark AF (1994) Effects of burning and grazing on sustainable utilization of upland snow tussocks (Chionochloa spp.) rangelands for pastoralism in south island, New Zealand. Aust J Bot 42:149-161

McIntire EJB, Hik DS (2002) Grazing history versus current grazing: leaf demography and compensatory growth of three alpine plants in response to a native herbivore (Ochotona collaris). J Ecol 90:348-359

McNaughton SJ (1983a) Compensatory plant growth as a response to herbivory. Oikos 40:329-336

McNaughton SJ (1983b) Physiological and ecological implications of herbivory. In: Lange OL, Nobel PS, Osmond CB, Ziegler Z (eds) Physiological plant ecology, vol 12C. Springer, Berlin, pp 657-677

Milchunas DG, Lauenroth WK (1993) Quantitative effects of grazing on vegetation and soils over a global range of environments. Ecol Monogr 63:327-366

Milchunas DG, Sala OE, Lauenroth WK (1988) A generalized-model of the effects of grazing by large herbivores on grassland community structure. Am Nat 132:87-106

Monteiro JAF (2010) Functional morphology and productivity of a Tussock grassland in the Bolivian Altiplano. PhD Thesis, University of Basel, Basel, p 62

Monteiro JAF, Hiltbrunner E, Körner C (2011) Functional morphology and microclimate of Festuca orthophylla, the dominant tall tussock grass in the Andean Altiplano. Flora 206:387-396

Patty L, Halloy SRP, Hiltbrunner E, Körner C (2010) Biomass allocation in herbaceous plants under grazing impact in the high semi-arid Andes. Flora 205:695-703

Pinheiro JC, Bates DM (2000) Mixed-effects models in S and S-PLUS. Springer, Heidelberg. http://www.springer.com/statistics/ statistical+theory+and+methods/book/978-1-4419-0317-4

Pugnaire FI, Haase P, Incoll LD, Clark SC (1996) Response of the tussock grass Stipa tenacissima to watering in a semi-arid environment. Funct Ecol 10:265-274

Rotundo JL, Aguiar MR (2008) Herbivory resistance traits in populations of Poa ligularis subjected to historically different sheep grazing pressure in Patagonia. Plant Ecol 194:121-133

Rowley J (1970) Effects of burning and clipping on temperature, growth, and flowering an narrow-leaved snow tussock. NZ J Bot $8: 263-282$

Sandquist DR, Ehleringer JR (1998) Intraspecific variation of dryout adaptation in brittlebush: leaf pubescence and timing of leaf loss vary with rainfall. Oecologia 113:162-169

Strauss SY, Agrawal AA (1999) The ecology and evolution of plant tolerance to herbivory. Trends Ecol Evol 14:179-185 
Team RDC (2009) R: a language and environment for statistical computing. In: 2.10 .0 edn. R Foundation for Statistical Computing, Vienna, Austria

Ursino N (2009) Above and below ground biomass patterns in arid lands. Ecol Model 220:1411-1418
Westoby M (1989) Selective forces exerted by vertebrate herbivores on plants. Trends Ecol Evol 4:115-117

Zuur AF, Ieno EN, Walker NJ, Saveliev AA, Smith GM (2009) Mixed effects models and extensions in ecology with R, First edition edn. Springer, New York 